\title{
Direct-to-Consumer Broadcast Advertisements for Pharmaceuticals: Off-Label Promotion and Adherence to FDA Guidelines
}

\author{
Kristina Klara, $B S^{7}$, Jeanie Kim, $\mathrm{JD}^{2,3}$, and Joseph S. Ross, $\mathrm{MD}, \mathrm{MH} \mathrm{S}^{3,4,5,6}$ \\ 1, Yale School of Medicine, New Haven, CT, USA; ${ }^{2}$, Yale Law School, New Haven, CT, USA; ${ }^{3}$, Collaboration for Research Integrity and Transparency \\ (CRIT) at Yale University, New Haven, CT, USA; ${ }^{4}$ Section of General Internal Medicine and the National Clinician Scholars Program, Yale School of \\ Medicine, New Haven, CT, USA; ${ }^{5}$ Department of Health Policy and Management, Yale School of Public Health, New Haven, CT, USA; ${ }^{6} \mathrm{Center}$ for \\ Outcomes Research and Evaluation (CORE), Yale-New Haven Hospital, New Haven, CT, USA.
}

BACKGROUND: Direct-to-consumer (DTC) advertisements for prescription drugs in the United States are regulated by the Food and Drug Administration (FDA). Off-label promotion, or the advertisement of a drug for an indication not approved by the FDA, is prohibited. Our objective was to examine the presence of off-label promotion in broadcast DTC ads and to assess their adherence to FDA guidelines mandating fair balance in presentation of risks and benefits and prohibiting misleading advertisement claims.

METHODS: All English-language broadcast DTC ads for prescription drugs that aired in the United States from January 2015 to July 2016 were obtained from AdPharm, an online collection of healthcare advertisements. Ad length was measured and adherence to FDA guidelines was assessed for several categories: key regulatory items, indicators of false or misleading ads, and indicators of fair balance in presentation of risks and benefits.

RESULTS: Our sample included 97 unique DTC ads, representing 60 unique drugs and 67 unique drug-indication combinations. No ads described drug risks quantitatively, whereas drug efficacy was presented quantitatively in 25 (26\%) ads. Thirteen (13\%) ads, all for diabetes medications, suggested off-label uses for weight loss and blood pressure reduction. The most commonly advertised drugs were indicated for the treatment of inflammatory conditions ( $n=12 ; 18 \%$ ), diabetes or diabetic neuropathy ( $n=11 ; 16 \%)$, bowel or bladder dysfunction $(n=6 ; 9 \%)$, and infections or allergic reaction $(n=6 ; 9 \%)$. More than three-quarters $(n=51 ; 76 \%)$ advertised drugs to treat chronic conditions.

CONCLUSIONS: Few broadcast DTC ads were fully compliant with FDA guidelines. The overall quality of information provided in ads was low, and suggestions of off-label promotion were common for diabetes medications. The impact of current DTC ads and off-label marketing on patient and prescriber decisions merits further scrutiny.

KEY WORDS: direct-to-consumer advertising; pharmaceutical promotion; off-label promotion; off-label marketing; FDA guideline adherence.

Electronic supplementary material The online version of this article (https://doi.org/10.1007/s11606-017-4274-9) contains supplementary material, which is available to authorized users.

Received May 31, 2017

Revised September 28, 2017

Accepted December 6, 2017

Published online February 26, 2018
J Gen Intern Med 33(5):651-8

DOI: $10.1007 /$ s11606-017-4274-9

(C) Society of General Internal Medicine 2018

\section{INTRODUCTION}

Since 1985, the US Food and Drug Administration (FDA) has allowed direct-to-consumer (DTC) advertising of drugs. ${ }^{1}$ Proponents argue that DTC advertising provides valuable information and empowers patients to make medical decisions, while critics claim that it undermines the patient-physician relationship, leads to inappropriate prescribing practices, and increases healthcare costs. ${ }^{2-4}$ Research has shown that DTC advertising for prescription drugs increases patient demand, prescribing, and sales for the advertised drugs. ${ }^{3,5-8}$ In 2015 , spending on DTC ads in the US reached \$5.6 billion. ${ }^{9}$ A small number of drugs make up most of the spending, and brandname prescription drugs that are more costly than generic alternatives tend to be the most highly advertised and promoted. ${ }^{10-12}$ Television DTC ads are becoming a more prominent means of marketing; it is estimated that US citizens watching an average amount of television may see nine drug ads per day, or up to $30 \mathrm{~h}$ of DTC ads each year. ${ }^{13,14}$

Although the FDA regulates the labeling and advertising of prescription drugs and requires drug companies to submit all promotional materials to the Office of Prescription Drug Promotion (OPDP), in light of capacity and resource constraints, the agency does not review every ad. ${ }^{4}$ Federal regulations prohibit ads that are false or misleading with respect to a drug's risks or benefits and require all promotional claims to be supported by evidence. In addition, all DTC advertising, regardless of the media, must present a fair balance between risk and efficacy information. While print advertisements must state all of the risks in the drug's FDA-approved label, broadcast DTC ads are only required to include the "major" risks, as long as (1) those risks are communicated in audio, and (2) the ad provides a source for consumers to access the FDAapproved labeling for the drug ("adequate provision"). $5,14,15$ Lastly, the FDA has traditionally taken the position that the Food, Drug, and Cosmetic Act restricts the promotion of an unapproved indication ("off-label" promotion), and federal 
regulations explicitly prohibit DTC ads from even suggesting an off-label use. ${ }^{5,16-18}$ Pharmaceutical companies have used the First Amendment to challenge certain restrictions on offlabel marketing. Recent federal court cases have permitted companies to promote off-label indications to physicians, thereby calling into question the FDA's authority to regulate off-label marketing, even with respect to DTC advertising. ${ }^{19-21}$

Previous studies of print, television, and online advertisements have found that many do not adhere to the regulations and guidelines set forth by the FDA. ${ }^{9,10,22-26}$ However, the most recent study was based on advertisements aired from 2008 to 2010 , examining the most strongly emphasized claim in each of 84 prescription drug ads and finding that of these, $55 \%$ were potentially misleading and $2 \%$ were false. ${ }^{24}$ To our knowledge, few studies have examined contemporary adherence of DTC ads to the regulations and guidelines set forth by the FDA, and none have examined the prevalence of suggestions of off-label promotion, which is particularly important given that regulatory standards for off-label promotion are currently being challenged in the courts. In the present study, we assess the degree to which recently aired DTC ads for prescription drugs adhered to FDA regulations and guidelines, and we examine whether off-label use was suggested.

\section{METHODS}

\section{Data Source and Sample}

We conducted a descriptive analysis of television DTC ads for prescription drugs aired in the US between January 2015 and July 2016. We obtained the ads in August 2016 from AdPharm, an online database of healthcare and pharmaceutical advertisements. ${ }^{27}$ The gallery includes ads for prescription and over-the-counter medications. AdPharm is updated daily, and major television networks are monitored regularly for new content. We limited our search to English-language DTC advertisements for prescription medications and removed all duplicate ads prior to analysis, such that the ad was represented only once in our sample. Duplicate ads were those that had the same length and script.

\section{Data Collection Instrument}

We created an ad data collection instrument with 40 items, of which 26 were derived from federal regulations or FDA guidance for broadcast ads, ${ }^{4,15,28}$ and 14 described additional characteristics of the ad or the drug advertised. Of these 26 items, 11 were identified as key regulatory requirements, seven were chosen as indicators of ads that were potentially false or misleading, and eight were chosen as indicators of ads that might be lacking in fair balance between presentation of risks and benefits. Of the 14 descriptive items, 10 were developed to characterize ad appeal, including the age and sex of the protagonist, whether there were real patients, whether there were celebrity patients, and whether the ad referenced savings or insurance coverage. We also examined whether there were abbreviations or animation/mascots, because the FDA is conducting research on whether animation impacts recall or perception of risk and benefit information. ${ }^{19}$ We collected the drug's trade and generic names, length of the ad, and initial date aired from the AdPharm website. ${ }^{20}$ Four items collected from the FDA website ${ }^{17}$ were chosen to describe the advertised drugs: whether the drug carried a black box warning, the initial FDA approval date for the drug, the approved indication(s) for use, and the type of condition treated by the drug. We defined a chronic condition as one lasting more than 1 year, an intermediate condition as lasting less than 1 year, and an acute condition as lasting less than 1 month. All other items were abstracted by viewing the ads. All items with justification for their inclusion and/or references can be found in the Online Supplementary Table.

\section{Data Abstraction}

Regulations require broadcast DTC ads to communicate "major risks" in the audio (or both audio and visual), along with adequate provision for viewers to find full risk information. Because there is no guidance on how to determine which risks are major, we assessed whether the ads included the information in the "Highlights of Prescribing" page of the drug's FDAapproved label, which is the first page. The Highlights page contains the following categories of information: contraindications and limitations of use, warnings and precautions (including black box warnings), and adverse events. We examined whether all items in each of these categories were presented in the broadcast ad. We also acquired the most recently approved product label for each drug at the time the commercial was aired from the FDA website, ${ }^{17}$ characterizing all suggested indications for use as FDA-approved (on-label) or off-label. In addition, we consulted the drug label to determine whether comparative claims made in the ads were mentioned in the label. If quantitative information was included in the ads, we characterized the type of data as relative risk reduction (RRR), absolute risk reduction (ARR), both, or neither.

\section{Evaluation and Reliability}

One author (KK) abstracted the information described above for all DTC ads, and a second author (JK) validated data abstraction for a random $20 \%$ sample. We measured reliability for binary variables by overall percentage agreement. For two continuous variables - time spent discussing risk and number of risk claims - we calculated percentage disagreement by dividing the median difference between the raters by the average risk time or average number of risk claims, respectively. Two authors (KK, JSR) jointly examined quantitative efficacy statements to determine whether they were presented as ARR, RRR, both, or neither, or whether the type of data was indeterminate. Overall percentage agreement for binary variables was $95 \%$, while agreement was $98 \%$ for time spent describing risks and $86 \%$ for number of risk claims. 


\section{Statistical Analysis}

We used descriptive statistics to characterize adherence to FDA guidelines, including key regulatory items and off-label promotion, indicators of potentially false or misleading ads, and indicators of ads potentially lacking in fair balance. All analyses were performed using Microsoft Excel (Microsoft Corp., Redmond, WA).

\section{RESULTS}

\section{Study Sample}

One hundred fifty-one DTC advertisements were identified, including 97 unique ads; 54 ads were excluded as duplicates. Among unique ads, 60 drugs were represented. Four drugs were advertised for more than one indication: adalimumab (Humira) was advertised for five indications, apixaban (Eliquis) for two, onabotulinumtoxin A (Botox) for two, and pregabalin (Lyrica) for two. Thus, there were 67 unique drugindication combinations.

Among the 67 ads with unique drug-indication combinations, the most commonly advertised drugs were indicated for the treatment of inflammatory conditions $(n=12 ; 18 \%)$, diabetes or diabetic neuropathy $(n=11 ; 16 \%)$, bowel or bladder dysfunction $(n=6 ; 9 \%)$, and infections or allergic reaction $(n=6 ; 9 \%)$. Other indications advertised included sexual dysfunction, psychiatric or neurological disorders, cardiovascular disease, and lung disease (Table 1).

More than three-quarters of unique drug-ad combinations $(n=51 ; 76 \%)$ advertised drugs to treat chronic conditions, whereas $12(18 \%)$ were for intermediate conditions and four $(6 \%)$ for acute conditions. Forty percent $(n=27)$ advertised drugs carrying black box warnings.

\section{Ad Characteristics}

The median advertisement length was $60 \mathrm{~s}$ (interquartile range [IQR], 60-90 s; Table 2). We used the ages and genders of the protagonists in each ad as a marker of the probable target population. Most of the protagonists were young $(n=36$; $37 \%)$ or middle-aged $(n=27 ; 28 \%)$. The majority of ads had female protagonists $(n=43 ; 44 \%)$ or included both male and female protagonists $(n=35 ; 36 \%)$. Four $(4 \%)$ ads did not contain a human protagonist. Sixty percent $(n=58)$ of advertisements made reference to potential savings on or payment for the drug. Seven ads (7\%) included a notice with instructions on reporting side effects and adverse events to the FDA, a practice that is required for print but not broadcast advertisements.

\section{Off-Label Promotion}

All advertisements included an approved use for the drug (Table 3). In addition to communicating an approved indication, $13 \%(n=13)$, which comprised five unique diabetes
Table 1 Characteristics of the Prescription Drugs for which Broadcast Direct-to-Consumer Ads Aired in the United States from January 2015 to July 2016

\begin{tabular}{ll}
\hline \hline Characteristic & $\begin{array}{l}\text { Unique drug-indication } \\
\text { combination }(\boldsymbol{n}=\mathbf{6 7})\end{array}$ \\
\hline Indication* $^{*}$ & No. $(\%)$ \\
Inflammatory conditions $^{\dagger}$ & $12(17.9)$ \\
Diabetes $^{\ddagger}$ & $11(16.4)$ \\
Bowel/bladder dysfunction $^{\S}$ & $6(9.0)$ \\
Infections/allergic reaction $^{\|}$ & $6(9.0)$ \\
Sexual dysfunction & \\
Psychiatric/neurological $^{\#}$ & $4(6.0)$ \\
Cardiovascular** $^{*}$ & $7(10.4)$ \\
Lung $^{\dagger \dagger}$ & $7(10.4)$ \\
Other & $6(9.0)$ \\
Condition type treated* & $8(12.0)$ \\
Chronic & No. $(\%)$ \\
Intermediate & $51(76.1)$ \\
Acute & $12(17.9)$ \\
Black box warning & $4(6.0)$ \\
Yes & No. $(\%)$ \\
No & $27(40.3)$ \\
Initial drug approval year & $40(59.7)$ \\
2012 and later & No. $(\%)$ \\
2007-2011 & $29(43.3)$ \\
2002-2006 & $8(11.9)$ \\
1997-2001 & $17(25.4)$ \\
Prior to 1997 & $6(9.0)$ \\
\end{tabular}

*Drugs that were advertised for $>1$ indication in the same ad were classified for the indication that accounted for the preponderance of use ${ }^{*}$ Rheumatoid arthritis, plaque psoriasis, psoriatic arthritis, inflammatory bowel disease

Type 1 diabetes, type 2 diabetes, diabetic neuropathy

Irritable bowel syndrome with diarrhea, overactive bladder, irritable bowel syndrome with constipation \& chronic idiopathic constipation, opioid-induced constipation

"Allergic reaction/anaphylaxis, infection prophylaxis post-chemotherapy, flu, toenail fungus, hepatitis $C$

${ }^{\top}$ Erectile dysfunction, erectile dysfunction with benign prostatic hyperplasia, dyspareunia

${ }^{\#}$ Depression, bipolar depression, Alzheimer's disease, multiple sclerosis, insomnia

**Anticoagulation, heart failure, high cholesterol

${ }^{H}$ Chronic obstructive pulmonary disease, asthma, small cell lung cancer, smoking cessation

${ }^{H}$ Acne, chronic dry eye, fibromyalgia, gastroesophageal reflux disease, chronic migraine, osteoporosis, birth control

medications, suggested non-FDA-approved-or offlabel — uses, all of which were for weight loss and/or reduction in systolic blood pressure.

\section{Key Regulatory Requirements}

All ads included the established drug name or ingredient information with the proprietary name; $95 \%(n=92)$ included the proprietary and established names/ingredient information for the same amount of time, and $97 \%(n=94)$ included the established name/ingredient information in type font that was at least half as large as the type font used for the proprietary name. Only 20\% ( $n=20)$ of ads used the established name in the audio portion of the ad, which is not required but suggested. Seventy-eight percent of ads $(n=76)$ described all risk information in audio, while $22 \%(n=21)$ had at least one risk in running text only. While the FDA requires at least one form of adequate provision in each broadcast ad, all but one ad $(n=$ 
Table 2 Characteristics of the Broadcast Direct-to-Consumer Ads for Prescription Drugs that Aired in the United States from January 2015 to July $2016(n=97)$

\begin{tabular}{ll}
\hline \hline Item & No. (\%) \\
\hline Portrays patient(s)/contains patient testimonial* $^{*}$ & $89(92)$ \\
Ad contains a real patient taking the drug \\
Ad contains a celebrity patient taking the drug \\
The patient in the ad speaks \\
Age of protagonist in the ad & $14(16)$ \\
Young & $8(9)$ \\
Middle & $55(62)$ \\
Older & $38(39)$ \\
More than one age group represented & $27(28)$ \\
No human protagonist & $7(7)$ \\
Sex of protagonist & $21(22)$ \\
Female & $4(4)$ \\
Male & $43(44)$ \\
Both & $15(15)$ \\
No human protagonist & $35(36)$ \\
Makes reference to savings on drug/insurance coverage & $4(4)$ \\
Uses an abbreviation for medical condition & $58(60)$ \\
Contains animation or mascots & $37(38)$ \\
Ad includes a notice with instructions on reporting side & $21(22)$ \\
effects to FDA & $7(7)$ \\
\hline
\end{tabular}

*Four ads did not contain human protagonists. Of the five Viagra ads included in this analysis, only one had a male patient present in the commercial

${ }^{\dagger}$ Parameter addressed only if preceding criteria were met; percentage is based on the number of ads meeting preceding criteria. For example, the percentage value for the ads containing a real patient is based on the number of ads in which patients were present $(n=89)$

${ }^{*}$ The protagonists for Namenda and Namzaric were the patient caretakers, and for all five Viagra ads, the protagonists were the female partner

96; 99\%) included all forms of adequate provision suggested by the FDA: a toll-free phone number to call for drug labeling, web address to access labeling, reference to a print ad for the drug, and a statement indicating that the viewer's physician could provide more information. One ad did not have a tollfree phone number but included all other suggested forms of adequate provision.

Table 3 Key Regulatory Elements Described in the Broadcast Direct-to-Consumer Ads for Prescription Drugs that Aired in the United States from January 2015 to July $2016(n=97)$

\begin{tabular}{|c|c|}
\hline$\overline{\text { Item }}$ & No. (\%) \\
\hline \multicolumn{2}{|l|}{ Naming } \\
\hline $\begin{array}{l}\text { Established drug name/ingredient info accompanies } \\
\text { proprietary name* }\end{array}$ & $97(100)$ \\
\hline $\begin{array}{l}\text { Established and proprietary names/ingredient info } \\
\text { displayed for the same amount of time* }\end{array}$ & $92(95)$ \\
\hline Established name/ingredient info is used in audio & $19(20)$ \\
\hline Established name/ingredient info appropriately sized* & $94(97)$ \\
\hline \multicolumn{2}{|l|}{ Adequate provision } \\
\hline Provides toll-free number to call for labeling ${ }^{\dagger}$ & $96(99)$ \\
\hline Provides web address to access labeling ${ }^{\dagger}$ & $97(100)$ \\
\hline Reference to a print ad for the $\operatorname{drug}^{\dagger}$ & $97(100)$ \\
\hline States that physician can provide more information ${ }^{\dagger}$ & $97(100)$ \\
\hline \multicolumn{2}{|l|}{ Off-label promotion and major risk information } \\
\hline Communicates an approved use* & $97(100)$ \\
\hline Markets off-label ${ }^{\ddagger}$ & $13(13)$ \\
\hline $\begin{array}{l}\text { Major risks/limitations of use presented in audio as } \\
\text { opposed to running text only* }\end{array}$ & $76(78)$ \\
\hline
\end{tabular}

*These items are specifically required by the FDA

${ }^{*}$ These items are suggested by the FDA to fulfill the "adequate provision" requirement

${ }^{7}$ This is specifically prohibited by the FDA

\section{Indicators of Potentially False or Misleading Ads}

Only $26 \%(n=25)$ of ads contained quantitative efficacy information (Table 4). Of these, $12 \%(n=3)$ provided ARR, $4 \%(n=1)$ provided RRR, 24\% $(n=6)$ provided both ARR and RRR, $52 \%(n=13)$ provided quantitative information that was neither ARR nor RRR, and 8\% ( $n=2)$ contained data that could not be classified, such as "In our largest study, when added to metformin, people lost on average up to 6.2 pounds." None of the commercials contained quantitative information regarding risks or side effects. Thirty-three percent $(n=27)$ of ads mentioned all contraindications and limitations of use in the drug's FDA-approved label, 59\% $(n=57)$ mentioned all adverse events, and 53\% $(n=50)$ included all warnings and precautions. Every ad for a drug that carried a black-box warning in its label communicated this safety warning.

Forty (41\%) ads mentioned clinical studies or clinical evidence, though only three of these (8\%) provided a citation for the study or the data. Fifteen (15\%) ads made comparisons to other therapies, and of these, $12(80 \%)$ made claims that were supported by information in the advertised drug's FDAapproved label.

\section{Indicators of Ads Potentially Lacking Fair Balance}

The median percentage of time spent describing risks was $45 \%$ (IQR, 39-52; Table 5). The median percentage of time

Table 4 Indications of Potentially False or Misleading Information Described in the Broadcast Direct-to-Consumer Ads for Prescription Drugs that Aired in the United States from January 2015 to July $2016(n=97)$

\begin{tabular}{|c|c|}
\hline Item & No. (\%) \\
\hline Provides quantitative information for efficacy/benefit & $25(26)$ \\
\hline Absolute risk reduction ${ }^{*}$ & $3(12)$ \\
\hline Relative risk reduction $^{*}$ & $1(4)$ \\
\hline Both absolute risk reduction and relative risk reduction ${ }^{*}$ & $6(24)$ \\
\hline Neither absolute risk reduction nor relative risk & $13(52)$ \\
\hline reduction $^{*} \quad *$ & \\
\hline Indeterminate $^{*}$ & $2(8)$ \\
\hline Quantitative information is provided for risks & $0(0)$ \\
\hline Ad mentions all contraindications and limitations of use ${ }^{\dagger}$ & $27(33)$ \\
\hline Ad mentions all adverse events & $57(59)$ \\
\hline $\begin{array}{l}\text { Ad mentions all warnings and precautions (including } \\
\text { boxed warnings) }\end{array}$ & $50(53)$ \\
\hline Mentions studies/clinical evidence & $40(41)$ \\
\hline Citation is provided for clinical evidence ${ }^{*}$ & $3(8)$ \\
\hline Makes comparative claims to other therapies & $15(15)$ \\
\hline Comparative info is included in the labeling ${ }^{*}$ & $12(80)$ \\
\hline $\begin{array}{l}\text { There is running text on the screen during risk info } \\
\text { that is not related to risk }\end{array}$ & $77(79)$ \\
\hline Risk information is accompanied by distracting visuals & $97(100)$ \\
\hline
\end{tabular}

* Parameter addressed only if preceding criteria were met; percentage is based on the number of ads meeting preceding criteria. For example, the percentage value for the ads containing a real patient is based on the number of ads in which patients were present (89)

${ }^{\dagger}$ Fourteen ads were for drugs that did not have any contraindications or limitations of use; percentage is determined from drugs that did have contraindications/limitations of use

${ }^{7}$ Two ads were for drugs that did not have any warnings or precautions; percentage is determined from drugs that did have warnings or precautions 
Table 5 Indications of Fair Balance Required in the Broadcast Direct-to-Consumer Ads for Prescription Drugs that Aired in the United States from January 2015 to July $2016(n=97)$

\begin{tabular}{|c|c|}
\hline Risk Time & $\begin{array}{l}\text { Median } \\
\text { (IQR) }\end{array}$ \\
\hline Percentage time spent describing risks $(\%)^{*}$ & $45(39-52)$ \\
\hline Percentage time spent on topics other than risk $(\%)^{*}$ & $58(45-61)$ \\
\hline Number of risk claims* & $16(12-23)$ \\
\hline Time spent/risk claim* & $2 \mathrm{~s}(1.6-2.3)$ \\
\hline Item & No. $(\%)$ \\
\hline Volume is the same during benefit and risk sections* & $97(100)$ \\
\hline $\begin{array}{l}\text { Background music is the same during benefit and risk } \\
\text { sections* }\end{array}$ & $96(99)$ \\
\hline $\begin{array}{l}\text { Announcer is the same for benefit and risk } \\
\text { information* }\end{array}$ & $56(58)$ \\
\hline \multicolumn{2}{|l|}{ Ad ends on a statement of ${ }^{\dagger}$} \\
\hline Benefit & $38(39)$ \\
\hline Risk & $17(18)$ \\
\hline Neither & $42(43)$ \\
\hline
\end{tabular}

*These items are related to the "fair balance" requirement from the FDA, and these specific examples of fair balance are provided as examples in guidance documents

${ }^{\top}$ The FDA recommends that risk information be put at the beginning or end of broadcast ads, where viewers are most likely to remember it

spent on other forms of communication, such as description of benefits or drug indication, was 55\% (IQR, 48-61). The median number of risks described in each ad was 16 (IQR 12-23), with a median of $2 \mathrm{~s}$ spent per risk claim (IQR 1.6$2.3)$. Forty-two percent of ads $(n=41)$ used a different announcer for risk and benefit information, all of the ads had the same audio volume level for the presentation of risk and benefit information, and all but one $(n=96 ; 99 \%)$ had the same background music playing through the description of the risk and benefit information. Thirty-nine percent of ads $(n=38)$ ended on a statement of benefit, $18 \%(n=17)$ ended on a statement of risk, and $43 \%(n=42)$ ended with neither risk nor benefit information. Ads that ended with neither benefit nor risk information ended with cost information or another neutral statement. In all ads, presentation of risk information was accompanied by distracting visuals, such as frequent scene changes or characters dancing and singing, and $79 \%(n=77)$ had running text on the screen during the audio risk presentation that was not related to risks, such as "See our ad in Weight Watchers." To illustrate representative examples of the types of quantitative data and slogans used in broadcast DTC ads, Table 6 includes selected excerpts from the ads.

\section{DISCUSSION}

Our study examined the degree to which prescription drug television DTC advertisements that aired between January 2015 and July 2016, adhered to regulations and FDA guidelines and whether there were suggestions of off-label promotion. Our findings demonstrate that the quality of information in DTC television ads is low: none described drug risks quantitatively; only one-quarter described drug benefits quantitatively; and suggestions of off-label promotion were common for diabetes medications. Though proponents argue that
Table 6 Illustrative Efficacy Statements/Ad Slogans from Broadcast Direct-to-Consumer Ads for Prescription Drugs that Aired in the United States from January 2015 to July $2016(n=97)$

\begin{tabular}{|c|c|}
\hline$\overline{\text { Drug }}$ & Efficacy statement/Ad slogan \\
\hline Victoza & $\begin{array}{l}\text { "Victoza is not approved for weight loss. In our largest } \\
\text { study, when added to metformin, people lost on } \\
\text { average up to } 6.2 \text { pounds." }\end{array}$ \\
\hline Stelara & $\begin{array}{l}\text { "Most people using Stelara saw } 75 \% \text { clearer skin, and the } \\
\text { majority were rated as cleared or minimal at } 12 \text { weeks." }\end{array}$ \\
\hline Botox & $\begin{array}{l}\text { Running text: "Botox prevents on average } 8 \text { to } 9 \text { headache } \\
\text { days and migraine/probable migraine days a month } \\
\text { (versus } 6 \text { to } 7 \text { for placebo)." }\end{array}$ \\
\hline Botox & $\begin{array}{l}\text { Screen shows text that says: "Adults using Botox had } \\
\text { fewer accidents than those who did not," and graph } \\
\text { shows that placebo had } 4 \text { daily leakage episodes and } \\
\text { Botox patients had } 3 \text { at week } 12 \text {. }\end{array}$ \\
\hline Jublia & $\begin{array}{l}\text { Narrator: "Fight it with Jublia!" Celebrity: "Oh, epic } \\
\text { moves, big J," said as the Jublia mascot fights a cartoon } \\
\text { toenail fungus. Narrator: "Fight it! Getting ready for } \\
\text { your close-up? Ask your doctor if Jublia is right for } \\
\text { you." }\end{array}$ \\
\hline
\end{tabular}

Chantix Running text: "In studies, $44 \%$ of CHANTIX users were quit during weeks 9 to 12 of treatment (compared to $18 \%$ on sugar pill)."

Prolia "I can tell you Prolia is proven to help protect bones from fracture, but the real proof? My doctor said Prolia helps my bones get stronger. Are your bones getting stronger?"

Movantik "You sound like you're ready for the movan-talk. Opioids block pain signals, but they can also block activity in the bowel, causing constipation. Movantik can help reduce constipation caused by opioid pain medications."

Neulasta "In a key study, Neulasta reduced the risk of infection from $17 \%$ to $1 \%$, a $94 \%$ decrease."

Opdivo Running text: "In a clinical trial, Opdivo reduced the risk of dying by $41 \%$ compared to chemotherapy (docetaxel). Half the Opdivo patients were alive at 9.2 months versus 6 months for chemotherapy (docetaxel)." Narrator: "It's not every day something this big comes along - a chance to live longer."

"A chance to live longer," is written in lights on skyscrapers.

Tamiflu "Prescription Tamiflu can help you get better 1.3 days faster. That's 30\% sooner." Running text: "In studies, Tamiflu helped shorten the time adults were sick by 1.3 days $(30 \%)$."

Trulicity Running text: "Trulicity is not a weight loss drug. In studies, people who lost weight lost 2-6 lbs on average."

Brilinta "Brilinta worked better than Plavix and even reduced the chances of dying from another one...I will take Brilinta today, tomorrow, and every day for as long as my doctor tells me. Don't miss a day of Brilinta."

Eliquis "I accept that I'm not 21. I accept I'm not the sprinter I was back in college. I even accept that I live with a higher risk of stroke due to Afib, a type of irregular heartbeat not caused by a heart valve problem. But I won't accept giving it less than my best, so if I can go for something better than warfarin, I will. Eliquis. Eliquis reduced the risk of stroke better than warfarin. Plus, it had less major bleeding than warfarin. Eliquis had both. That really mattered to me."

Entresto "For people with heart failure, tomorrow is not a given. But Entresto is a medicine that helps make more tomorrows possible. In the largest heart failure study ever, Entresto helped more people stay alive and out of the hospital than the leading heart failure medicine."

Farxiga "And although it's not a weight loss or blood pressure drug, Farxiga may help you lose weight and may even lower blood pressure when used with certain diabetes medicines."

Humira "This is my body of proof. Proof of less joint pain and clearer skin. This is my body of proof that I can fight psoriatic arthritis from the inside out with Humira...It's proven to help relieve pain, stop further joint damage, and clear skin in many adults." 


\section{Table 6. (continued)}

\begin{tabular}{|c|c|}
\hline Drug & Efficacy statement/Ad slogan \\
\hline Invokana & $\begin{array}{l}\text { "Imagine loving your numbers. Discover once-daily } \\
\text { Invokana. It's the \#1 prescribed SGLT2 inhibitor that } \\
\text { works to lower A1C, and it's proven to lower A1C } \\
\text { better than Januvia...And while it's not for lowering } \\
\text { systolic blood pressure or weight loss, it may help you } \\
\text { with both." }\end{array}$ \\
\hline Linzess & $\begin{array}{l}\text { "Linzess is thought to help calm pain-sensing nerves and } \\
\text { accelerate bowel movements." Simultaneous running } \\
\text { text: "This was seen in animal studies and the relevance } \\
\text { to humans is unknown." }\end{array}$ \\
\hline Osphena & $\begin{array}{l}\text { "I can't believe I'm admitting this on national TV, but } \\
\text { someone had to. After menopause, sex became } \\
\text { extremely painful. I spoke to my doctor. She } \\
\text { recommended I try Osphena. It treats moderate to severe } \\
\text { painful sex due to menopause...Let's open the dialogue. } \\
\text { Ask your doctor about Osphena. Tell them Patty sent } \\
\text { you." }\end{array}$ \\
\hline Pradaxa & $\begin{array}{l}\text { Screen shows red fish that represent blood cells traveling } \\
\text { through water-filled pipes. "Don't just go with the flow. } \\
\text { Go with Pradaxa, the only blood thinner that lowers } \\
\text { your risk of stroke better than warfarin and has a specific } \\
\text { reversal treatment." }\end{array}$ \\
\hline Viagra & $\begin{array}{l}\text { Narrator: "About half of men over } 40 \text { have some degree of } \\
\text { erectile dysfunction." Running text: "Data from } \\
\text { Massachusetts Male Aging Study. Of } 1290 \text { respondents, } \\
52 \% \text { reported some degree of erectile dysfunction } \\
\text { (ED)." }\end{array}$ \\
\hline
\end{tabular}

DTC advertising is educational and empowering for consumers, ${ }^{2-4}$ our findings suggest that the information provided is unreliable and potentially misleading. The promotion of offlabel indications, poor quality of information, distracting risk presentations, and the fact that risks are never quantified could distort the perception of benefit and risk information.

We found that DTC ads frequently contained information that could be considered misleading, which is consistent with prior research. ${ }^{9,10,22-26}$ In a previous study, Faerber et al. examined 84 prescription drug advertisements and found that, of the most emphasized claims in each ad, $43 \%$ were objectively true, $55 \%$ potentially misleading, and $2 \%$ false. ${ }^{24}$ Though in our study we did not utilize the same methods to identify potentially misleading information, we did find that the quality of information presented, particularly the quantitative data, was low. For instance, the following are efficacy statements from two ads: "Victoza is not approved for weight loss. In our largest study, when added to metformin, people lost on average up to 6.2 pounds;" and "Most people using Stelara saw 75\% clearer skin, and the majority were rated as cleared or minimal at 12 weeks." Both claims are vague and difficult to interpret, providing conflicting descriptions of findings. While we found potentially misleading information in the broadcast ads in our sample, we did not identify any claims that were blatantly false. Kaphingst et al. analyzed 23 television ads from 2001 and found that only 1 of 23 ads presented risk information in a quantitative way; none of the ads in our sample presented risks in quantitative terms. ${ }^{22}$ Lastly, another interesting finding was that $60 \%$ of ads referenced methods of payment and potential savings. Though drug coupons may defray the cost of brand-name drugs for patients in the short term, these offers are typically time-limited. Moreover, the societal costs of using drug coupons may be significant, as patients with drug coupons are foregoing the opportunity to use less expensive alternatives. ${ }^{29}$

In December 2016, the FDA issued warning letters to the makers of Toujeo (insulin glargine injection) and Otezla (apremilast), citing television ads that included misleading representations of risk. The FDA stated that ads for both drugs included distracting scenes and music as well as running text on screen during the risk presentation, many of which were present in the ads we studied, and all of which are discouraged by FDA guidance, ${ }^{28}$ as they impair the viewer's ability to absorb risk information. ${ }^{30,31}$ These concerns were justified by recently published research suggesting that when DTC ads list severe side effects along with those that are most frequent, consumer perceptions of the overall risk severity are diluted. ${ }^{32}$ Due to budget constraints, it might be unrealistic for the FDA to review all television commercials for prescription drugs before they are aired. However, it would be helpful if there were clearer and more detailed regulations and guidance for DTC broadcast ads, particularly with respect to providing quantitative risk information, along with better FDA enforcement of current guidance. Moreover, the FDA could consider charging a "user" fee to ensure there are sufficient resources to hire personnel that can review each ad prior to its air date.

Our findings regarding off-label promotion have not been previously demonstrated. Suggestions of off-label use, a practice that has been expressly prohibited in prescription drug DTC advertising, occurred in $13 \%$ of ads in our sample. All of these ads marketed drugs indicated for the treatment of type 2 diabetes, and suggested potential benefits of use, including weight loss and blood pressure reduction; the drugs include canagliflozin (Invokana), liraglutide (Victoza), dapagliflozin (Farxiga), empagliflozin (Jardiance), and dulaglutide (Trulicity). For example, the off-label promotion for dapagliflozin claims: "And although it's not a weight loss or blood pressure drug, Farxiga may help you lose weight and may even lower blood pressure when used with certain diabetes medicines." In March 2015, the consumer advocacy group Public Citizen sent a letter to the FDA citing off-label marketing in print advertisements for five type 2 diabetes drugs, ${ }^{27}$ four of which we also identified in our study. To date, the FDA has not issued warning letters to the manufacturers of these drugs for off-label marketing. While we cannot explain our findings, perhaps once a drug in a certain class is marketed off-label, the others may seem inferior unless they also suggest off-label benefits. Moreover, if one company starts suggesting off-label uses and is not issued any warning or fine, other companies with similar drugs are at a disadvantage if they do not do the same.

There are important limitations of our study to consider. First, FDA regulations and guidelines for broadcast DTC ads are not always clearly defined. For example, broadcast advertisements are required by regulations to present only the major risks in the commercial as long as they meet the adequate provision requirement by providing a source for viewers to access the full drug labeling. ${ }^{15}$ However, the criteria for 
determining which risks are most important are vague. Therefore, we focused our study on how many ads included all of the information in the following categories from the drug's approved label: contraindications and limitations of use, warnings and precautions, and adverse events. Second, the assessment of DTC ads is potentially subjective. However, we used a standardized protocol for assessing ads and found excellent inter-rater reliability using our data collection instrument. Lastly, the interpretation of the FDA guidelines for DTC ads can potentially be considered subjective. By creating clearer, more objective requirements, the FDA could better regulate broadcast DTC advertising.

Overall, we found that few ads were fully compliant with FDA guidelines for DTC advertising, and that the quality of information presented in broadcast DTC ads for prescription drugs was low. Data were rarely provided to support benefit claims, the risks were never quantified, and off-label promotion occurred. Taken together, these findings have important implications for patients and clinicians. Broadcast DTC advertising could lead patients to make healthcare decisions and request certain expensive, brand-name medications based on ads containing low-quality and incomplete information. It has been shown that DTC advertising for prescription drugs increases patient demand for those drugs, which include a disproportionate number of more expensive brand-name formulations. Moreover, this increase in patient demand leads to increased prescribing and sales of the advertised drugs. ${ }^{3,5-8}$

Our findings are similar to previous reports, indicating that the quality of DTC advertising has not improved since it was first studied. This may be due to the lack of enforcement of DTC advertising requirements. It has been suggested that the FDA review television commercials for prescription drugs prior to their release to ensure that ads are more informative for the public. ${ }^{14}$ By enacting such a program and by enforcing more objective requirements for DTC advertisements, the FDA could better protect consumers. In addition, the impact of off-label marketing via DTC ads on patient and prescriber decisions merits further study.

Acknowledgements: This project was supported in part by the Laura and John Arnold Foundation, which established the Collaboration for Research Integrity and Transparency (CRIT) at Yale University and supports Ms. Kim and Dr. Ross. The sponsor played no role in the design of the study, analysis or interpretation of findings, drafting of the manuscript, or review or approval of the manuscript prior to submission. The authors assume full responsibility for the accuracy and completeness of the ideas presented.

Corresponding Author: Joseph S. Ross, MD, MHS; Section of General Internal Medicine and the National Clinician Scholars Program, Yale School of Medicine, New Haven, CT, USA (e-mail: joseph.ross@yale.edu).

Author Contributions All authors were responsible for the conception and design of this work, participated in the analysis and interpretation of the data, and critically revised the manuscript for important intellectual content. Ms. Klara conducted the statistical analysis and drafted the manuscript. Ms. Klara and Ms. Kim were responsible for the acquisition of data. Dr. Ross provided supervision.

\section{Compliance with Ethical Standards:}

Conflict of Interest: In the past 36 months, Dr. Ross has received research support through Yale University from Johnson \&. Johnson to develop methods of clinical trial data sharing; from Medtronic, Inc. and the Food and Drug Administration (FDA) to develop methods for postmarket surveillance of medical devices (UO1FD004585); from the Food and Drug Administration to establish the Yale-Mayo Clinic Center for Excellence in Regulatory Science and Innovation (CERSI) program (U01FD005938); from Blue Cross Blue Shield Association to better understand medical technology evaluation; from the Centers for Medicare \& Medicaid Services (CMS) to develop and maintain performance measures that are used for public reporting; and from the Agency for Healthcare Research and Buality to examine community predictors of healthcare quality (RO1HSO22882). All remaining authors declare that they do not have a conflict of interest.

\section{REFERENCES}

1. Donohue J. A history of drug advertising: the evolving roles of consumers and consumer protection. Milbank Q. 2006;84(4):659-99.

2. Mintzes B. Advertising of prescription-only medicines to the public: does evidence of benefit counterbalance harm? Annu Rev Public Health. 2012;33:259-77.

3. Hollon MF. Direct-to-consumer advertising: a haphazard approach to health promotion. JAMA. 2005;293(16):2030-3.

4. AMA Calls for Ban on DTC Ads of Prescription Drugs and Medica Devices. 2015. Available at: https://www.ama-assn.org/content/amacalls-ban-direct-consumer-advertising-prescription-drugs-and-medicaldevices. Accessed 27 Nov 2017.

5. Gilbody S, Wilson P, Watt I. Benefits and harms of direct to consumer advertising: a systematic review. Qual Saf Health Care. 2005;14(4):246-50.

6. Donohue JM, Berndt ER, Rosenthal M, Epstein AM, Frank RG. Effects of pharmaceutical promotion on adherence to the treatment guidelines for depression. Med care. 2004;42(12):1176-85.

7. Rosenthal MB, Berndt ER, Donohue JM, Epstein AM, Frank RG. Demand Effects of Recent Changes in Prescription Drug Promotion. 2003; Available at: https://kaiserfamilyfoundation.files.wordpress.com/ 2013/01/demand-effects-of-recent-changes-in-prescription-drug-promotion-report.pdf. Accessed November 27, 2017.

8. Layton JB, Kim Y, Alexander GC, Emery SL. Association Between Direct-to-Consumer Advertising and Testosterone Testing and Initiation in the United States, 2009-2013. JAMA. 2017;317(11):1159-66.

9. Kim H. Trouble Spots in Online Direct-to-Consumer Prescription Drug Promotion: A Content Analysis of FDA Warning Letters. Int $\mathrm{J}$ Health Policy Manag. 2015;4(12):813-21.

10. Adams C. Fair Balance and Adequate Provision in Direct-to-Consumer Prescription Drug Online Banner Advertisements: A Content Analysis. J Med Internet Res. 2016;18(2):e33.

11. Donohue JM, Cevasco M, Rosenthal MB. A decade of direct-toconsumer advertising of prescription drugs. N Engl J Med. 2007;357(7):673-81.

12. Greenway T, Ross JS. US drug marketing: how does promotion correspond with health value? BMJ. 2017;357:j1855.

13. Brownfield ED, Bernhardt JM, Phan JL, Williams MV, Parker RM. Direct-to-consumer drug advertisements on network television: an exploration of quantity, frequency, and placement. J Health Commun. 2004;9(6):491-7.

14. Ventola CL. Direct-to-Consumer Pharmaceutical Advertising: Therapeutic or Toxic? P T. 2011;36(10):669-684

15. U.S. Food and Drug Administration. Guidance for Industry: ConsumerDirected Broadcast Advertisements. August 1999; Available at: http://www. fda.gov/downloads/Drugs/GuidanceComplianceRegulatoryInformation/ Guidances/UCM070065.pdf. Accessed November 27, 2017.

16. Kesselheim AS, Avorn J. Pharmaceutical promotion to physicians and First Amendment rights. N Engl J Med. 2008;358(16):1727-32.

17. Kesselheim AS. Off-Label Drug Use and Promotion: Balancing Public Health Goals and Commercial Speech. Am J Law Med. 2011;37(2-3):225-57.

18. Code of Federal Regulations 21 C.F.R. 202.1(e)(6)(i)2017. https://www. accessdata.fda.gov/scripts/cdrh/cfdocs/cfcfr/CFRSearch.cfm?fr=202.1 
19. Kapczynski A. Free Speech and Pharmaceutical Regulation-Fishy Business. JAMA Intern Med. 2016;176(3):295-6.

20. Mazer D, Curfman G. Health Affairs Blog: FDA Sanctions Off-Label Drug Promotion. July 2016; Available at: http://healthaffairs.org/blog/2016/07/ 19/fda-sanctions-off-label-drug-promotion/. Accessed November 27, 2017.

21. Kim J, Kapczynski A. Promotion of Drugs for Off-label Uses: The US Food and Drug Administration at a Crossroads. JAMA Intern Med. 2017;177(2): 157-8.

22. Kaphingst KA, DeJong W, Rudd RE, Daltroy LH. A content analysis of direct-to-consumer television prescription drug advertisements. J Health Commun. 2004;9(6):515-28.

23. Macias W, Pashupati K, Lewis LS. A wonderful life or diarrhea and dry mouth? Policy issues of direct-to-consumer drug advertising on television. Health Commun. 2007;22(3):241-52.

24. Faerber AE, Kreling DH. Content analysis of false and misleading claims in television advertising for prescription and nonprescription drugs. J Gen Intern Med. 2014;29(1):110-8.

25. Mirkin JN, Lowrance WT, Feifer AH, Mulhall JP, Eastham JE, Elkin EB. Direct-to-consumer Internet promotion of robotic prostatectomy exhibits varying quality of information. Health Aff (Millwood). 2012;31(4):760-9.

26. Korenstein D, Keyhani S, Mendelson A, Ross JS. Adherence of pharmaceutical advertisements in medical journals to FDA guidelines and content for safe prescribing. PloS One. 2011;6(8):e23336.

27. Almashat $\mathbf{S}$, Wolfe $\mathbf{S}$, Carome $\mathbf{M}$. Public Citizen Letter to FDA. March 2015; Available at: http://www.citizen.org/documents/2250.pdf. Accessed November 27, 2017.
28. U.S. Food and Drug Administration. Guidance for Industry: Presenting Risk Information in Prescription Drug and Medical Device Promotion. May 2009; Available at: http://www.fda.gov/downloads/Drugs / GuidanceComplianceRegulatoryInformation/Guidances/UCM155480. pdf. Accessed November 27, 2017.

29. Ross JS, Kesselheim AS. Prescription-drug coupons-no such thing as a free lunch. N Engl J Med. 2013;369(13):1188-9.

30. Wanis S, Falter MJ. U.S. Food and Drug Administration Warning Letter To the Makers of Otezla (apremilast). December 2016; Available at: http://www. fda.gov/downloads/Drugs/GuidanceComplianceRegulatoryInformation/ E n f or c e m e n t A c t i viti e s b y F D A / WarningLettersandNoticeofViolationLetterstoPharmaceuticalCompanies/ UCM533292.pdf. Accessed November 27, 2017.

31. Kalola A, McLawhorn M. U.S. Food and Drug Administration Warning Letter to the Makers of Toujeo. 2016; Available at: http://www.fda.gov/ downloads /Drugs / GuidanceComplianceRegulatoryInformation/ $\mathrm{E} n \mathrm{f}$ or c e m e $\mathrm{nt} \mathrm{A} \mathrm{c} \mathrm{t} \mathrm{i} \mathrm{vi} \mathrm{t} \mathrm{i} \mathrm{e} \mathrm{s} \mathrm{b} \mathrm{y} \mathrm{F} \mathrm{D} \mathrm{A} \mathrm{/}$ WarningLettersandNoticeofViolationLetterstoPharmaceuticalCompanies/ UCM533300.pdf. Accessed November 27, 2017.

32. Sivanathan N, Kakkar $\mathbf{H}$. The unintended consequences of argument dilution in direct-to-consumer drug advertisements. Nat Hum Behav. 2017;1:797-802. 